\title{
Detección prenatal de sindrome de Down a través de la integración de pruebas realizadas durante el primero y segundo trimestre
}

Integrated Screening for Down's Syndrome Based on Tests Performed during the First and Second Trimesters. Wald N, Watt H, Hackshaw A. N Eng J Med 1999; 341: 461-7.

\section{Objetivo}

Evaluar la capacidad de predicción de los diferentes métodos de rastreo para sindrome de Down integrados en un nuevo esquema o "prueba integrada".

\section{Diseño}

Se analizaron las propiedades de la "prueba integrada" comparándola con los rastreos ya existentes para el primero y el segundo trimestre, así como sus variedades.

\section{Lugar}

Department of Enviromental and Preventive Medicine, Wolfson Institute of Preventive Medicine, St. Bartholomew's and the Royal London School of Medicine and Dentistry. Gran Bretaña.

\section{Pacientes}

Para el rastreo del primer trimestre se tomaron datos de mediciones de ßHCG y proteína plasmática A asociada al embarazo (PAPP-A) de 77 embarazadas con un feto con sindrome de Down y 383 controles; y la medida del pliegue nucal de 326 fetos con sindrome de Down y 95476 controles. Para el rastreo durante el segundo trimestre se utilizaron los dosajes de $\propto$ feto proteína, BHCG, estriol no conjugado e inhibina A en 77 embarazadas con un feto con sindrome de Down y 385 controles.

\section{Descripción de las pruebas}

Para el rastreo durante del primer trimestre se utiliza la medición ecográfica del pliegue nucal fetal entre las 10 y las 14 semanas, al que se le puede agregar el dosaje de BHCG y PAPP-A. Para el tamizaje del se- gundo trimestre se dosa $\propto$ feto proteína, BHCG, estriol no conjugado (triple test) y en algunos centros, también inhibina A (cuádruple test). El test de referencia o estándar de oro es el análisis cromosómico prenatal o posnatal.

\section{Medición de los resultados}

Se determinó la tasa de detección o sensibilidad (proporción de afectados con resultado positivo del test), la tasa de falsos positivos y las chances (odds) de tener un niño Down luego de un resultado positivo del test (la relación de los casos afectados con los no afectados).

\section{Resultados}

Con una una tasa de falsos positivos de $5 \%$, la prueba integrada tuvo una sensibilidad de $94 \%$ (69\%, 76\% y $85 \%$ para el triple y el cuádruple tamizaje del segundo trimestre y para el primer trimestre respectivamente). Utilizando un punto de corte de 1:120 la tasa de falsos positivos fue de $0.9 \%$ y la tasa de detección (sensibilidad), de $85 \%$. Para lograr una tasa de detección similar durante el primero y el segundo trimestre, el punto de corte debió fijarse en 1:540 y 1:630 respectivamente, con tasas de falsos positivos de $4.9 \%$ y $9.8 \%$. La chance de Down de la prueba integrada fue de 1:9; para el tamizaje del primer trimestre, 1:45 y para el del segundo, 1:89.

\section{Conclusiones}

La estrategia integrada detecta más casos de sindrome de Down con mucho menos falsos positivos que las estrategias disponibles actualmente.

\section{COMENTARIO}

En un principio, la edad materna fue el único método para identificar a las madres con probabilidad de tener un feto afectado con sindrome de Down, ya que la misma aumenta con la edad.

En 1984, Merkatz describió que las madres portadoras de un feto con sindróme de Down tenían nivels de $\propto$ feto proteína en el suero $25 \%$ menores que los de las madres controles. Desde entonces, se han incorporado una serie de marcadores serológicos ${ }^{1-2}$ (estriol no conjugado, BHCG, inhibina A, PAPP-A) y ecográficos ${ }^{3}$ (pliegue nucal), que permiten calcular el riesgo de cada embarazo individual de tener un niño afectado por síndrome de Down al término del mismo. Este cálcuto deriva del riesgo materno correspondiente a cada edad y de un modelo basado en la distribución Gaussiana de los diferentes marcadores.

El uso de esta metodología puede ana lizarse en diferentes escenarios. Desde una perspectiva social, la búsqueda de fetos afectados con enfermedades cromosómicas o malformaciones tiene íntima relacion con las ideas, valores y conceptos que cada sociedad tiene sobre la salud, la enfermedad y la discapacidad; y con la forma en que cada sociedad desea distribuir los siempre limitados recursos para la aten- ción de la salud. En este contexto y con un marco normativo coherente; tras la discusión de los aspectos éticos 4 y legales pertinentes, la "prueba integrada" representa un mejoramiento en las herramientas existentes ya que permite la detección de mayor número de fetos afectados con menor pérdida de fetos sanos por procedimientos invasivos. En el marco de los protocolos de atención prenatal, se recomienda el uso de procedimientos diagnósticos invasivos por encima de los 35 años. La "prueba integrada" disminuiría significativamente el número de mujeres sometidas a estos procedimientos, evitando la pérdida de fetos sanos, así como los costos concomitantes. En la población menor de 35 años (población de bajo riesgo) permite una mayor detección ya que estas mujeres, de otra manera, no realizarían ningún procedimiento invasivo.

Desde el punto de vista individual es indispensable el asesoramiento objetivo sobre los beneficios y las limitaciones del mismo; explicando que un resultado desfavorable puede hacer necesaria una evaluación más detallada a través de métodos diagnósticos más invasivos con sus correspondientes riesgos. 